\title{
E1 desarrollo económico de China comunista
}

J O H N G. G U R L E Y es profesor de Economía en la Universidad de Stanford, California, y director del American Economic Review. Este trabajo fue preparado durante el periodo en que el profesor Gurley fuc miembro del Centre for the Advanced Study in the Behavioural Sciences.

Es preferible decirlo de inmediato, y no veladamente más adelante; China comunista no ha fracasado en su desarrollo económico. El actual levantamiento en China no pretende ocuitar un presunto naufragio económico. Por el contrario, la situación económica de China es excelente, en comparación con lo que era hace diez, veinte o cincuenta años. La economía china ha prosperado enormemente desde 1949; su expansión se ha mantenido al nivel de aquellos paises que dictan el ritmo económico en el mundo; son muy pocos los países pobres que han logrado tanto progreso en un frente económico tan amplio como lo ha hecho China comunista. Este punto de vista puede ser impopular, pero no me parece exagerado.

Algunas de las bases del desarrollo económico en China comunista pueden encontrarse en sus empresas industriales: maquinarias, equipos, estructuras. Pero el crecimiento económico chino no puede, a mi juicio, ser correctamente interpretado sólo en esos términos, sin hacer referencia a los logros obtenidos en materia de educación, medicina y salud pública e investigación científica. Aun cuando para un mero economista resulte difícil enjuiciar sobre estas bases, es probable que en el desarrollo económico de China las ideas hayan sido más importantes que las máquinas o, por lo menos, lo sean, analizado el asunto a largo plazo. No puede subestimarse el papel vital que la ideología ha desempeñado en el crecimiento económico chino, por más que ello no constituya un juicio evaluable matemáticamente.

La maquinaria, la educación, ia salud, las ideas, he aht los ingredientes del desarrollo chino, cada uno de los cuales intento considerar. 


\section{UNA MIRADA AL PASADO}

Es cierto que el desarrollo económico chino, sobre bases sostenidas, se inició en 1949, con el advenimiento comunista, pero antes ya hubo cierto progreso industrial esporádico ${ }^{1}$. Algunas de sus primeras industrias llegaron con los imperialistas occidentales, terminada la Guerra del Opio, en 1842. Ese hecho y las posteriores coerciones y el uso de fuerzas armadas abrieron más ampliamente el país a los inversionistas y comerciantes extranjeros. Se establecieron docenas de puertos sujetos a tratados mediante los cuales los extranjeros dejaban de estar bajo la jurisclicción del gobierno chino y las firmas extranjeras se liberaban de todo control chino. Desde allí se inició la presión extranjera hacia el interior, para establecer empresas milnufactureras y luego construir ferrocarriles y formar compañías mineras. La mayor parte de las inversiones directas recayeron en firmas con estrechas conexiones con el comercio exterior, en empresas comerciales y navieras, en bancos clestinados a financiar ese comercio; en minas de carbón para los barcos británicos, en líneas ferroviarias, servicios de utilidad pública en los puertos en que se operaba bajo tratados especiales, en industrias textiles y en compañías de seguros.

Luego de la ocupación anglo-francesa de Pekín, en 1860, el Gobierno Ch'ing respondió a la amenaza imperialista estableciendo sus propias fábricas de armamentos, a lo que siguió la formación de otras empresas industriales. A fines de siglo, a pesar de que habia en China una amplia variedad de firmas inclustriales, en la práctica existian en muy pequeño número, de limitada escala de operaciones y concentradas en algunos pocos puntos a lo largo de la costa. La totalidad de este esfuerzo tuvo muy poca gravitación sobre la vasta economía agraria de China; no logró tampoco ningún progreso en aliviar la pobreza, enfermedades y analfabetismo que han azotado al campesinado chino desde los comienzos cle su historia.

Durante esos años, no tuvo lugar un desarrollo económico sostenido, debido a que la mayor parte del excedente económico fue absorbido por el consumo suntuario, por las guerras internas y externas, el pago de indemnizaciones, intereses y utilidades a los extranjeros. El consumo de suntuarios se alimentaba mediante el pago de rentas e intereses a la aristocracia dueña de la tierra y por impuestos y apremios a la burocracia oficial. Las guerras locales se financiaban con impuestos y préstamos externos. Las guerras exte: riores eran ganadas por los extranjeros, quienes luego cobraban indemnizaciones. De la suma de todo esto se desprende que poco o

¿Chiming Hou, Foreign Investment and Economic Development in China, 1840-1937; Albert Feverwerker, China's Early Industrialization. 
nada quedaba para la formación de un capital nacional. Sin embargo, si incluso hubiera habido excedentes disponibles, la ineficiencia y corrupción del Gobierno Ch'ing difícilmente hubieran hecho uso positivo de tales fondos.

Desde 19ll, año en que cayó la dinastia Ch'ing, hasta 1927, en que llegó al poder el gobierno nacionalista de Chiang Kai-shek, China vivió un período de desorganización política y económica, sin un gobierno central fuerte. Incluso el propio régimen de Chiang, amenazado por la invasión japonesa, enfrentando continuas batallas con pequeños líderes locales, además de su constante lucha contra los comunistas chinos, estuvo siempre lejos de constituir una fuerza unificada. El pequeño progreso industrial logrado en esos años también se limitó a áreas pequeñas y, prácticamente, no rozó a la gran masa china; la industria moderna formaba un delgado ribete orillando una de las economias más pobres y miserables del mundo. Para China propiamente tal, en la práctica no hubo -o si se dio fue en un grado mínimo-, desarrollo económico entre los años 1930 y 1940; en cambio, sí hubo una gran inflación.

Las causas inmediatas de la citada inflación fueron los enormes aumentos en los gastos gubernamentales y el pésimo sistema tributario, frente a la invasión japonesa ${ }^{2}$. La debilidad del sistema tributario no se debía tan sólo a lo anticuada que resultaba en sí misma la estructura existente, o a la pérdida de ciudades que cayeron. en manos de los japoneses, o a la desorganización que traía consigo la lucha, sino que también reflejaba el conflicto de intereses de clases y la corrupción dentro de las filas del propio Kuomintang. Los crecientes déficit presupuestarios se financiaban casi en su totalidad mediante la creación de moneda, principalmente nuevas emisiones. En consecuencia, la afluencia nominal de dinero se elevó fuertemente después de 1937, pero no pudo mantenerse al mismo ritmo de ascenso de los precios, que llegó al 20\% mensual durante la Segunda Guerra Mundial, para subir luego en 2.500 veces en los tres años siguientes. Durante los últimos meses antes del colapso total y de la huida de Chiang a Formosa, el índice de precios tạmbién se disparó y desapareció en lontananza.

\section{POLf́ticas ECONÓMICAS COMUNISTAS}

Los comunistas detuvieron la hiperinflación a mediados de 1950, para comenzar entonces la ruta de la reconstrucción y del desarrollo

'Kia-ngau Chiang, The Inflationary Spiral: The Experience in China, 1939-1950; Shun-hsin Chou, The Chinese Inflation 1937-1949; y Arthur Young, China's Wartime Finance and Infletion $1937 \cdot 1945$. 
económico. Tal como se desarrollaron los acontecimientos, China comunista dio muestras de ser una de las economías de más rápida expansión en el mundo durante la década iniciada en 1950. El ritmo anual de aumento de la producción fue probablemente de alrededor del $9 \%$, aun cuando en esa cifra son determinantes los mínimos niveles de actividad económica registrados a comienzos de la década, y las frenéticas presiones para aumentar la producción que tuvieron lugar a raíz de la política del Gran Salto Adelante, a fines de dicha década. Posteriormente, el ritmo de expansión disminuyó y luego la economía china inició una tendencia descendente debido a los sucesivos desastres en las cosechas a partir de 1959; a la ausencia de incentivos en la vida de las comunas; a ineficiencias en la política del Gran Salto Adelante y, finalmente, al retiro de casi la totalidad de los técnicos soviéticos a mediados cle 1960. La producción puede o no haber disminuido algo en 1960, pero sin duda declinó, y probablemente en forma sustancial, al año siguiente. Desde 1962 o 1963, la economía china ha vuelto a acelerar su ritmo de expansión, pero a una tasa de desarrollo inferior a la lograda en la década iniciada en 1950. En la actualidad, China comunista aparece batiendo nuevos records en la mayor parte del frente económico, agricultura, industria y comercio exterior ${ }^{3}$.

Los logros espectaculares obtenidos en la década de 1950 se basaron, en gran parte, en un ambicioso programa de inversiones que cubrió en mucho mayor escala el sector industrial que el agrícola. Durante la década señalada, la inversión fue del orden del $25 \%$ a $30 \%$ del valor de la producción nacional, lo que constituye una tasa excepcionalmente alta para un país subdesarrollado; la mayor parte de los países pobres no logran capitalizar más allá de un $10 \%$ a un $15 \%$ del producto nacional.

Sin embargo, estos fuertes gastos de inversión, además de establecer la base del crecimiento económico, crearon a su vez fuertes presiones inflacionarias, dirigidas hacia los bienes de consumo y servicios, especialmente a los productos alimenticios. Dado que la inversión en agricultura había sido mínima, los comunistas intentaron incrementar la producción agrícola mediante una reorganización política y social, cuya meta era aumentar los incentivos y la eficiencia del campesinado. Las principales innovaciones en este sentido fueron reformas agrarias, equipos de ayuda mutua, cooperativas agrícolas elementales y de tipos más avanzados y las comunas popu-

${ }^{3}$ T. C. Liu y K. G. Yeh, The Economy' of the Chinese Mailand; S. Ishikawa, National Income and Capital Formation in Mainland China; John Gurley, Economic Development, Investment, and Saving in Communist China (mimeografiado); Alexander Eckstein, Communist China's Economic Growth and Foreign Trade; números recientes del Far Easlern Economic Review. 
lares. De hecho, se anotaron varios éxitos, pero, ẹn definitiva, se llevó demasiado lejos y demasiado rápido el proceso de formación de las comunas, especialmente si se considera que debieron enfrentar pésimas condiciones climáticas. Después de 1960, los comunistas neutralizaron algunas características de esta reorganización e incrementaron las inversiones tanto en la agricultura como en la industria liviana. Después de la retirada soviética, en 1960, el desarrollo se ha llevado a efecto más bien siguiendo una línea propiamente china que un molde stalinista.

Estas fueron las soluciones que se intentaron en el sector abastecimiento. Desde el punto de vista de la demanda, el fuerte programa de inversiones llevaba implícito una restricción en la demanda por bienes de consumo, o dicho en otros términos, la necesidad de un esfuerzo de ahorro interno equivalente a la inversión. Los comunistas habian sido testigos del proceso de devastación derivado de la hiperinflación que los condujo al podèr, de ahí que se decidieran a no intentar obtener los ahorros requeridos mediante un proceso inflacionario. En lugar de ello, incrementaron fuertemente las entradas por concepto de impuestos y disminuyeron los consumos gubernamentales, generando de esta manera ahorros en el sector gubernamental; usaron de los controles directos y de la manipulación de los precios relativos para obtener grandes utilidades en las empresas estatales, la mayor parte de las cuales volvian a incorporarse al presupuesto, aumentando así el ahorro fiscal; estimularon el ahorro individual mediante la creación de inversiones atractivas, que incluyeron cláusulas que implicaban poder adquisitivo, ciertos tipos de loterías, etc.; establecieron miles de nuevas oficinas bancarias en el pais; finalmente, por un tiempo pudieron emplear ahorro extranjero, de la Unión Soviética, en su programa de inversiones. Aun cuando los abastecimientos de bienes de consumo no se expandieron vigorosamente después de 1953, la demanda fue restringida en la medida suficiente como para impedir un incremento significativo en los precios $^{5}$.

\section{INVERSIÓN Y AHORRO}

Tal como ya lo he dicho, la mayor parte de los países subdesarrollados ostentan un buen resultado si logran invertir entre un $10 \%$ y un $15 \%$ de su producto nacional. A ese nivel comenzó China comu-

\footnotetext{
KKenneth Walker, Planning in Chinese Agriculture; Kuo-chun Chao, Agrarian Policy of the Chinese Communist Party 1921-1959; Dwight Perkins, Market Control and Planning in Communist Ghina.

sperkins, ibid., p. 158.
} 
nista a principios de la década iniciada en 1950, pero, luego, la relación inversión-producción alcanzó al $20 \%$ y continuó incrementándose hasta llegar casi al $40 \%$ en 1958-59. Los porcentajes de inversión en relación con la producción han sido inferiores en la década iniciada en 1960, pero, en tudo caso, siguen siendo muy superiores a los niveles medios registrados en las zonas subdesarrolladas del mundo De ahí que sean las inversiones, y efectuadas en gran escala, el factor que explica las elevadas tasas de crecimiento de la producción en la década de 1950, y su desarrollo renovado, aun cuando a un ritmo más modesto, después de 1962.

¿Cómo se financió esta inversión? ¿De dónde provino el ahorro? Potencialmente, puede derivarse de fuentes domésticas, en cuyo caso aparecería como ahorro individual o de negocios, o como un excedente en la recepción de impuestos en relación con los consumos guberizmentales; o puede provenir de ahorro externo, que se revelaría a rravés de un exceso de importaciones sobre las exportaciones. Habria que considerar esta última posibilidad en primer lugar.

¿En qué medida China tuvo acceso al ahorro externo? Si bien la respuesta a esta pregunta es incierta, las recientes investigaciones demuestran que es probable que China haya dispuesto de un saldo muy pequeño o de ninguna clase de excedentes de importaciones durante el periodo 1952-63, y esto podría afirmarse también para el período más largo de 1950-656. De manera que es poco probable que China haya financiado su desarrollo en una medida significativa sobre la base de ahorro externo durante el periodo indicado, considerado como un total. Pero, en cambio, hay pocas dudas en cuanto a que la tasa de crecimiento de China, por lo menos hasta 1957, se vio estimulada por sus excedentes de importación y por el enorme componente de capital-equipo en dichas importaciones, Ia mayor parte de las cuales provenian de la. Unión Soviética. De ahí que, y especialmente después de 1960, su tasa de desarrollo se viera afectada, ya que tuvo que recurrir a excedentes de exportaciones para cancelar deudas a la Unión Soviética y, al mismo tiempo, extender ayuda a otros países, cuando era probable que sus propias exportaciones de bienes de capital fueran superiores a sus importaciones de este tipo de mercaderías. Es por eso muy probable que las mayores tasas de crecimiento registradas en los primeros años y las inferiores anotadas en los años posteriores fueran influidas en forma significativa por el comercio exterior y los factores de ayuda externil.

'A. Eckstein, op. cit.; John Gurley, The Economy of China: A Guided Tour Through Sixleen Studies (mimeografiado). 
En realidad, sin embargo, la mayor parte del ahorro de China, destinado a su programa de inversiones, proviene de entradas presupuestarias, las que se elevaron en 11 veces entre 1950 y 1960. Las fuentes de entrada de incremento más rápido fueron las utilidades y reservas para amortización de las empresas estatales. En 1950, dichas entradas alcanzaban sólo al $15 \%$ del total de entradas presupuestarias, pero, en 1960, ya llegaban casi a dos tercios del total. Este rápido incremento se debió a la ampliación del control estatal sobre las empresas industriales, a los precios relativamente altos de los productos industriales, al bajo valor de la mano de obra y al acrecentamiento de las reservas por concepto de amortización basadas en los aumentos de capital. Los ahorros gubernamentales financiaron una creciente proporción del total de inversión durante la década, desde alrededor de un $50-60 \%$ al comienzo, hasta alcanzar tal vez a un $90 \%$ al final ${ }^{7}$. Durante la actual década, no cabe duda que China ha continuado financiando el grueso de sus inversiones mediante entradas presupuestarias, descansando, para estos efectos, fundamentalmente en las utilidades de las empresas estatales.

Parte del ahorro provino del sector cooperativo particular, principalmente de los hogares individuales y de las Comunas ( 0 , con anterioridad a éstas, de las cooperativas de productores agrícolas). El ahorro bruto de este sector financió alrededor del $20 \%$ del total de la inversión bruta durante los primeros años de la década, pero dicha proporción disminuyó a un $15 \%$ en 1956-57 y, finalmente, a un $10 \%$ en 1959. La mayor parte de este ahorro fue usado por las Comunas en su propia inversión real, y muy poco de éste fue a contribuir a la formación de capital del sector estatal. De ahí que cada uno de los dos sectores descansara en sus propios ahorros para los efectos de la formación de capital; ninguno de los dos prestó sus ahorros al otro en cantidades significativas ${ }^{8}$.

Considerando las tres formas de ahorro en su totalidad resulta que, a comienzos de la década de 1950, al menos la mitad del total de las inversiones se financió mediante ahorros gubernamentales, una cuarta parte tal vez se derivó de ahorro externo, y la otra cuarta parte de ahorro del sector privado. Hacia fines de la citada década, la participación de ahorro fiscal había subido al $90 \%$, la correspondiente al ahorro externo había disminuido a cero y la del sector privado a un 10\%. El panorama, a partir de 1960, deja de ser tan claro; en todo caso es indudable que el ahorro fiscal continúa dominando en el rubro inversiones, y probablemente ahora más que nunca. El ahorro

'George Ecklund, Financing the Chincse Government Budget: Mainiand China 1950-1959. Gurlcy. Economic Development... 
externo ha pasado a ser un elemento negativo, puesto que China ha proporcionado ayuda a otros países subdesarrollados y ha dejado de recibir toda clase de ayuda externa, al mismo tiempo que ha cancelado grandes deudas a la Unión Soviética. Es difícil pronunciarse sobre el ahorro del sector cooperativo particular, pero es probable que no haya variado su participación en relación a lo ocurrido a fines de la década de 1950, e incluso puede haber registrado un ligero aumento.

\section{Determinantes DEL aumento de LA PRODUCción}

Aun cuando resulte descorazonador, hasta el momento sólo he logrado determinar dos elementos fundamentales. En primer lugar, China comunista llevó a efecto un importante programa de inversiones, especialmente en la década de 1950, el cual estuvo centrado en la industria pesada. En segundo lugar, financió estos gastos de inversión fundamentalmente gracias al ahorro fiscal, aun cuando en los primeros años la ayuda externa proporcionada por la Unión Soviética fue un factor importante. Ahora me gustaría preguntar en qué medida los gastos de inversión ayudaron a aumentar la producción total de China. ¿Es esta la razón por la cual la producción aumentó tan rápidamente?

En primer lugar, observemos las posibilidades. La producción total puede incrementarse mediante adiciones en los insumos -capital, abastecimiento de mano de obra y administración y tierra cultivabley por mejoras en la calidad de tales insumos: mediante cantidad y calidad. La cantidad de capital se incrementa mediante inversiones; la mano de obra aumenta en la medida del crecimiento de la población; y la tierra utilizable puede extenderse y ser recuperada. La calidad del capital puede elevarse mediante innovaciones y otros avances tecnológicos; la calidad de la mano de obra puede mejorarse mediante la educación, entrenamiento en el trabajo mismo y mejor asistencia médica; la tierra puede mejorarse mediante la aplicación de fertilizantes, mejores sistemas de rotación de los cultivos, prevención de las inundaciones; las técnicas de administración pueden mejorarse mediante entrenamiento y experiencia. Las economías de escala también pueden lograrse con la expansión industrial. La idea de repasar esta lista tiene como objeto xecalcar el hecho de que la inversión en bienes de capital es sólo un elemento, aun cuando tal vez uno de gran importancia clentro del proceso del desarrollo.

¿Htasta qué punto importante? Es imposible afirmarlo con certiclumbre. Pero sí podemos hacer algunos cálculos grosso modo. Durante la década de 1950 , la producción aumentó en un promedio 
anual del $9 \%$. Al mismo tiempo, el capital creció en alrededor de un $71 / 2 \%$ al año, la mano de obra en tal vez un $3 \%$ y el aumento de la tierra disponible probablemente no alcanzó a ser significativo. Si suponemos que el producto marginal de la mano de obra fue equivalente al doble del capital -lo que puede ser una aseveración razonablemente cercana a la verdad- resulta que el capital contribuyó en un $21 / 2 \%$ al aumento de la producción del $9 \%$, y que la mano de obra contribuyó en un $2 \%$. De ahí que, si el análisis es correcto, los insumos básicos - en cuanto cantidad-corresponden a la mitad de la tasa de crecimiento; la otra mitad proviene de la calidad, de los avances técnicos, progresos en salud y educación, y factores similares?.

Ninguno de estos resultados es preciso; incluso hay posibilidades de que se encuentren lejos de la realidad. En todo caso, indican con bastante firmeza que el incremento de capital durante la década de 1950 en China, aun cuando constituyó un factor de importancia, no fue el elemento dominante en el proceso de desarrollo de la producción; que la mayor parte de estos progresos debe asignarse a otros factores que elevaron la productividad, especialmente la correspondiente a la mano de obra. Pasaré ahora a tratar esos otros elementos del desarrollo, los factores de calidad.

\section{EdUGación, investigación científica Y SALud}

Mi punto de vista personal es que el progreso lazrado por los comunistas chinos en los terrenos de la educación, investigación científica y salud ha significado un enorme incremento en la productividad de la mano de obra y, por tanto, en el aumento de la producción nacional. Esto, naturalmente, es en parte una intuición, si bien está basada en algunos conocimientos de los progresos chinos en esos terrenos y en lo que dichos progresos han significado económicamente en otros países. Carezco de tiempo para discutir este último punto, pero podría delinear brevemente los progresos chinos en esas áreas.

Para empezar, se ha registrado un inmenso avance en lo que a educación se refiere. En la actualidad, el número de niños y adultos jóvenes ubicados en instituciones educacionales de tiempo completo es superior, entre seis y ocho veces, a la matrícula de 1949. En las escuelas primarias, el número se ha elevado de unos 25 millones a 150 millones aproximadamente, incluyendo a la casi totalidad de los niños de las zonas urbanas y a una gran mayoría de los niños de sectores rurales. La

\footnotetext{
'T. C. Liu, "Quantitative Trends in the Economy of the Chinese Mainland, 1952-1963", mimeografiado, 1965, pp. 53, 126-128; Chi-ming Hou, "Manpower Employment and Unemployment in Communist China, 1949-1957", mimeografiado, 1965, pp. 41, 46; John Gurley, Economic Development..., op. cit.
} 
matrícula en escuelas secundarias sólo equivale a un décimo de la córrespondiente a las primarias, pero dicha matrícula de 15 millones debe compararse con la de un millón en el período en que los comunistas llegaron al poder. Los estudiantes de educación superior totalizan hoy entre 1,5 y 2 millones; hace 17 años alcanzaban apenas a un puñado de personas ${ }^{10}$.

Fuera de la educación de tiempo completo, existe una gran proporción de estudiantes cle medio tiempo; estos últimos pasan la mitad de su jornada en las escuelas y la otra mitad trabajanclo. Este tipo de educación se inició en algunas de las grandes ciudades y muy luego se amplió a las zonas campesinas. También existe educación en las horas libres, que permite a los obreros el tomar cursos que cubren una extensa gama de tcmas, después de las horas de trabajo. De hecho, si el concepto escolaridad se extiencle para incluir no sólo a los anteriormente señalados, sino también a los grupos de estudiantes organizados por las comunas, fábricas, comités de barrios y el ejército, podremos afirmar que hay escuelas en toclas partes de China, incluso podriamos aseverar que China, en sí misma, es una gran escuela.

La educación no sólo implica aprender a leer y escribir, aunque esto sólo ya era tremendamente importante para un país con casi el $80^{\circ} \%$ de su población analfabeta en 1949. También significa educación socialista, uno de cuyos aspectos es el de pensar científicamente. Un hombre de ciencia británico, C. G. H. Oldham, quien estuvo en China en 1964 y luego en 1965, destacó recientemente la importancia de aquello11:

"Este proceso de cambio social ha sido poco comprendido, asi como tampoco está claro el papel que desempeña la ciencia en esta transformación. Pero existe evidencia suficiente para pensar que la ciencia puede constituir un importante catalizador en este proceso de cambio. Los chinos creen sin duda alguna que este es el caso, y están haciendo un gran esfuerzo para reemplazar las supersticiones de la vieja China por pensamiento científico y racional. En tiempos pasados, los campesinos consideraban que una cosecha enferma significaba una visita de los dioses, "y por tanto, nada hacían por mejorarla. En la actualidad, cada equipo de producción en la comuna que visité, tenía a uno de sus miembros entrenado para reconocer cualquier peste común, insectos dañinos, o plantas enfermas,

${ }^{10}$ Chu-yuan Cheng, Scienlific and Engineering Manpower in Communist China; C. H. G. Oldham, "Science and Education", Bulletin of the Alomic Scicnlisls, June 1966; Leo A. Orleans, "Education and Scientific Manpower", en Scicnces in Communist China; Stewart Fraser (ed.), Chinese Communist Education; ver también los articulos sobre educación de William $T$. Liu (cd.), Chinese Socicly Under Communism: A. Reader.

11Oldham, op. cil., p. 48. 
así como para saber qué medidas tomar en caso que las circunstancias lo recomendaran.

"En todas partes de China se le enseña al pueblo que las leyes de la naturaleza no sólo pueden ser comprendidas por el hombre, sino que además éste puede hacer uso de estos conocimientos para sus propios fines. La significación de esta comprensión en una escala masiva puede ser, en definitiva, uno de los más importantes logros de los comunistas chinos".

La educación está concebida no sólo para inculcar una actitud científica - lo que aparece incidentalmente incluido en el espíritu de la obra del Presidente Mao- sino que además para producir cientificos. En la China precomunista, los favorecidos y capaces se dedicaban a actividades literarias, artísticas o políticas; muy pocos sabían algo acerca de la ciencia y la tecnología. Los comunistas han cambiado esto, promoviendo el acceso al terreno científico, con el objeto de elevar la productividad y por razones de defensa nacional. Desde 1949, el sistema educacional ha producido más de un millón de graduados en ciencias e ingeniería. Además, alrededor de 8.000 estudiantes fueron enviados a la Unión Soviética y Europa Oriental para perfeccionamiento universitario, y recientemente algunos han sido enviados a Francia e Inglaterra. Los comunistas, además, han entrenado intensivamente y han utilizado a la mujer en el terreno científico, las que hoy cubren un $25 \%$ de la totalidad del personal ocupado en esa actividad. Los conocimientos científicos han sido ampliamente divulgados, habiéndose registrado considerable progreso en el desarrollo de nuevas ramas de la ciencia y la tecnología, tales como la física nuclear, radioelectrónica y tecnología ultrasónica.

Un experto norteamericano en este dominio estima que el rápido desarrollo de la inclustria pesada en China se encuentra estrechamente ligado a los 400.000 estudiantes de ingeniería graduados después de 1949; que el acelerado progreso en la industria química se debe en parte al "constante aumento de la mano de obra de alta especialización técnica en este terreno" y que lo mismo es válido para la producción de petróleo, defensa nacional y muchas otras industrias ${ }^{12}$. Habría que agregar que los 11.000 expertos soviéticos, que vivieron en China durante la década iniciada en 1950, constituyeron una enorme ayuda en gran parte de estas industrias.

De vez en cuando deben decirse cosas negativas acerca de China comunista, y las hay en su sistema educacional. Existe el adoctrinamiento político; la instrucción relativamente pobre en los aspectos

12Cheng, op. cit., p. 270. 
relacionados con ciencias sociales y humanísticas; el número aún pequeño de científicos de primera categoría que produce su sistema educacional; el sacrificio general que se hace de la calidad en aras de la cantidad; el relativo desprecio por la investigación pura; la distorsión de los objetivos científicos por la actividad polf́tica.

Respecto a este último punto, un químico soviético que trabajó en China en 1958 y 1960, describió muchas de esas distracciones del trabajo en su libro Un Cientifico Soviético en China. Al margen de las innumerables e interminables reuniones políticas, los principales cientificos eran obligados a ejercer labores manuales cada cierto tiempo, fuera de las continuas campañas que parecían no terminar nunca. Durante su primera estada en China, en calidad de Asesor del Instituto de Qufmica de Pekín, dio cuenta del siguiente divertido incidente ${ }^{13}$;

"Desde hacía un tiempo había notado las grandes hojas de papeles coloreados cubiertos con ideogramas a la entrada del Instituto de Química, ejemplos del famoso tatzepao, que generalmente consiste en dos a tres hojas. Pero, imaginense mi sorpresa cuando, al llegar una mañana, encontré cada muralla del vestíbulo y corredor cubiertas de hojas multicolores. Al segundo día, el mar de papel había subido las escaleras y, al tercer día, cubria todo el segundo piso. Al parecer, las paredes de cada corredor no eran suficientes para soportar todo aquello que los chinos querian decir, porque luego encontré un cordel tendido en el medio del hall, con tatzepaos colgados, como si se tratara de ropa tendida para secar... El tiempo ocupado en producir tatzepaos significó que cada miembro del Instituto debió descuidar su trabajo normal no menos de dos semanas. Durante la duración de esta campaña en particular, cada miembro académico debió contribuir con diez hojas cada uno, y cada trabajador manual, con cinco hojas".

Si el único objetivo de los comunistas chinos fuera el de incrementar la producción nacional, lo anterior sẹía indiscutiblemente una pérdida de tiempo, tal como lo considera Klochko, el químico soviético. Pero, tal como lo haré notar en seguida, la meta económica no es, bajo ningún concepto, la única; los comunistas demuestran ser perfectamente capaces, en determinados momentos, de sacrificar parte de la producción para lograr otros objetivos.

Los progresos de China en los terrenos de la medicina y salud pública son, de todos, tal vez los que más impresionan. Estos progresos han sido atestiguados por varios expertos norteamericanos y mu-

19Mikhail A. Klochko, Soviet Scientist in China, pp. 73.74. 
chos recientes visitantes de China. Por ejemplo, G. Leslie Willox, un médico canadiense, visitó escuelas de medicina, hospitales, institutos de investigación, una fábrica, una comuna. En todas partes encontró equipo de buena calidad, elevado nivel y excelente atención médica; en todo comparable a los niveles canadienses. Tomó nota de que Ios chinos han dado especial importancia a todo lo relacionado con salud pública ${ }^{14}$ :

"Las enfermedades constitulan uno de los principales problemas de China, habiéndose logrado grandes éxitos en la prevención de epidemias. La mortalidad infantil ha disminuido hasta ser comparable a las tasas canadienses. Prácticamente, se han eliminado enfermedades como cólera, sarampión, tifus y venéreas. Se ha conseguido controlar la esquistosomiasis, una infección parasitaria muy corriente en la zona tropical sur de China. Los excrementos humanos son sometidos a procesamiento, por razones sanitarias, antes de ser usados como abono. Los médicos están bien entrenados en asuntos de salud pública, pero su esfuerzo sería inútil si no existiera paralelamente la intensiva propaganda radial y conferencias a grupos, con el objeto de enseñar y dirigir a la totalidad de la población en un programa masivo de toma de conciencia respecto de los problemas sanitarios y de la salud".

Una primera etapa de este programa masivo la constituyó la campaña contra las cuatro pestes: mosquitos, moscas, ratas y gorriones. Nuestro quimico soviético, Klochko, se encontraba en Pekín aquel dia domingo de abril en que, a su juicio, se habfan abierto todas las puertas del infierno, al iniciarse una parte de aquella campaña. La describe como sigue ${ }^{15}$ :

"Fui despertado temprano en la mañana por unos gritos de mujer que helaban la sangre. Corrl hacia mi ventana, desde donde divisé a una mujer joven que corría de un lado a otro por el techo de la casa de al lado, moviendo frenéticamente un palo de bambú que llevaba atado a él una gran sábana. De repente, la mujẹ cesó de gritar, al parecer para tomar aliento, pero, momentos después, abajo en la calle, comenzó a órse un tambor y ella reanudó sus gritos escalofriantes y el loco flamear de sư extraña bandera. Esto continuó durante varios minutos más; pararon los támbores y la

1"G. Leslic Willox, "Observations on Medical Practices", Bulletin of the Atomic Stientists, junio 1966, p. 52. Ver asimismo, William Y. Chen, "Medicine and Public Health", -in Sciences in Communist China, pp. 384, 397-99.

25Klochko, op. cit., p. 72. 
mujer se quedó en silencio. Me di cuenta ehtonces que, en todos los pisos superiores del hotel, mujeres vestidas de blanco agitaban sábanas y toallas que se suponia debian evitar que los gorriones se. posaran en el edificio.

"Este fue el comienzo de la campaña antigorriones. Durante todo el día se oyeron tambores, disparos, gritos, se vio el flamear de ropas de carna, pero en ningún momento logré ver ni un solo gorrión. No podría decir si acaso los pobres pajarillos habrían presenticlo el peligro mortal, y habian volado con anterioridad hacia terrenos más seguros) o si acaso para empezar nunca había habido gorriones. Pero la batalla continuó sin descanso hasta la tarde, con todo el personal del hotel movilizado y participando -mensajeros, empleados de la administración, intérpretes, camareras, todo el mundo".

Los gorriones sufrieron los efectos de dicha campaña, la mayor parte de las moscas fue liquidada, las ratas purgadas. Aun cuando todo esto no incrementó mayormente la tasa de crecimiento de la producción, el resto de los factores en juego seguramente lo ha hecho. Cuando la mayor parte de una nación se alfabetiza; cuando la educación formal es accesible a creciente número de jóvenes; cuando los adultos en cantidad que alcanza a las decenas de millones participan de programas educativos en sus tiempos libres; cuando se realizan serios esfuerzos por producir científicos e ingenieros; cuando se expanden grandemente las facilidades médicas y los programas de salud pública; cuando se barre con mitos y supersticiones; cuando la mayor parte de un pueblo tiene una diaria noche de descanso en una cama y bajo techo; cuando todas estas cosas ocurren juntas y en una escala significativa, la vida económica de un país necesariamente progresa en forma sustancial.

\section{LoS ASPECTOS ECONÓMICOS DEL MAOÍSMO}

He dejado las cosas más importantes para el final, debido fundamentalmente a que, por tratarse de un tema en gran parte marginal al área económica, implica para mi mayores dificultades para enfrentarlo. El tema podría llamarse "los aspectos económicos del maósmo". En términos muy generales, tiene que ver con la relación entre la ideología y el desarrollo económico. Sin embango, en parte también tiene que ver con la relación entre los tipos de personas que produce una sociedad determinada, y su progreso económico: la relación entre el desarrollo de seres humanos y el desarrollo de cosas materiales. Al 
referirme al "desarrollo de seres humanos" no quiero significar aquello que nosotros actualmente llamamos "inversión en capital humano" -salud y educación, temas sobre los cuales ya he hablaclo- sino más bien, la transformación espiritual del hombre, la formación del hombre comunista.

Los maoistas han dado a esto gran énfasis, durante todo el tiempo. Según su punto de vista, las masas poseen una enorme reserva inexplotada de creatividad, talento y energía. Esta enorme fuerza potencial no puede liberarse mediante egoístas incentivos materiales, sino sólo a través de incentivos morales. Los maoístas creen que, si cada persona se entrega a servir a todos los seres humanos, podrá liberarse esta enorme reserva de talento y energía, lo que traería consigo el rápido desarrollo de los aspectos materiales. Si, por el contrario, cada persona trabaja egoístamente por el logro de cosas materiales, no podrá realizarse la fuerza potencial de las masas y, por tanto, habrá escaso desarrollo en el sentido material. Si esa energía es liberada, el hombre pasará a ser mucho más importante que las máquinas y las armas; "el progreso económico, el poder nacional y la transformación social ya no dependerán solamente de prerrequisitos materiales"1". Aclemás, si así ocurre, podrá lograrse una sociedad igualitaria y sin clases, puesto que para motivarla sólo serán necesarios mínimos incentivos materiales. Finalmente, si la liberación de esa energía se produce, puede reducirse el actual interés por personal ultraespecializado, expertos $y$ profesionales, pues cada persona será capaz de muchas tareas, manuáles e intelectuales, sea en marcos urbanos o rurales ${ }^{1 \tau}$.

En la actualidad, por medio de la Revolución Cultural, los maoístas continúan su campaña de liberación de las inmensas energías que guardan las masas, apelando a los mensajes contenidos en los llamados "tres artículos constantemente leídos": Sirve al Pueblo; En Memoria de Norman Bethune; y el Viejo Hombre Tonto que Remorió las Montañas ${ }^{18}$. En estos artículos, la persona ideal carece de egoísmos, de miedo a la adversidad y siempre está al servicio del pueblo; se le compara muy favorablemente con su contrapartida bunguesa. La Revista "Pekín Informa" (Pekin Review) hizo tal comparación de la manera siguiente ${ }^{19}$ :

"La médula de la concepciöin de la vida en el mundo proletario está en el concepto de la completa devoción al interés público, en

\footnotetext{
10Benjamín Schwartz, "Modernisation and the Maoist Vision", Chine Quarlerly, encromarzo, 1965.

${ }^{17}$ Schwartz, op. cit. También tuve el beneficio de discusioncs solure esto con el Profesor Maurice Meisner.

18Estas se cncuentran en The Selected Works of Mao Tse-tung, Peking.

${ }^{2}$ Peking Review, February 17, 1967.
} 
el concepto de servix al pueblo sin reservas, en el espíritu comunista de total devoción a los demás, sin pensar en sí mismo. La médula de la concepción de la vida en el mundo burgués está en el concepto del propio interés antes que nada, del egoísmo, de la promoción de intereses personales a expensas del resto y de un extremo individualismo. . La actual gran revolución cultural proletaria en China, en última instancia, es la gran revolución ideológica para erradicar la ideología burguesa y adoptar la ideología proletaria, para erradicar el interés përsonal y adoptar el interés común. . Sólo cuando un hombre elimina completamente el concepto burgués del interés personal y establece firmemente el concepto proletario de la devoción al interés común, se encuentra en situación de descartar todo pensamiento que lo lleve a la búsqueda de fama y' éxito personal, de perder el miedo a la adversidad y a la muerte, y estar capacitado para entregarse totalmente a los demás, sin ningún pensamıento para sí mismo, para servir al pueblo total y enteramente...".

Según los maoístas, un hombre como el descrito era Norman Bethune, un cirujano canadiense, miembro del partido comunista de su pais. Se fue a Yenán en la primavera de 1938, con el objeto de ayudar al pueblo chino en su Guerra de Resistencia contra el Japón. Alli contrajo un envenenamiento de la sangre mientras operaba soldados heridos, luego murió en la provincia de Hopei, el 12 de noviembre de 1939. Alrededor de un mes más tarde, Mao hizo un discurso en memoria de Bethune ${ }^{20}$ :

"El espíritu del camarada Bethune, su total devoción a los demás, sin pensar nunca en sí mismo, se demostró en el sentido ilimitado de la responsabilidad en su trabajo y en su infinita cordialidad $y$ calor hunlano hacia todos los camaradas y el pueblo. Cada comunista debe aprender de él. No son pocos aquellos que son irresponsables en su trabajo, prefiriendo lo liviano a lo pesado, entregando a otros las cargas pesadas y escogiendo al mismo tiempo las tareas más fáciles para sí mismos. En cada momento piensan primero en ellos, antes que en los demás. Cuandio hacen alguna pequeña contribución, se llenan de orgullo y alardean de ella por temor a que el resto no se entere...

"Sólo estuve una vez con el camarada Bethune. Luego me escribió muchas cartas. Yo, sin embargo, estaba muy ocupado y sólo le escribí una vez y ni siquiera sé si recibió esa carta. Estoy profunda-

speking Reviciv, February 17, 1967. 
mente dolido con su muerte. Hoy todos lo conmemoramos, lo que demuestra con qué prófundidad su espiritu inspira a cada persona. Debemos aprender de su sentido de absoluta abnegación. Con ese espíritu, todos pueden ser útiles al pueblo. La habilidad cle un hombre puede ser pequeña o grande, pero și tiene ese espíritu, ya es noble y puro, un hombre de integridad moral y por sobre los intereses vulgares, un hombre que constituye un valor para el pueblo".

¿Tienen las masas talento y energía sin límites a la esjera de ser liberados por este tipo de llamados? No lo sé, pero puede haber una o dos claves sugerentes en ese extraordinario perfodo conocido como El Gran Salto Adelante. En mi opinión, dicho episodio fuc notable; no como estima la mayor parte de loș expertos occidentales, por su fracaso, sino más bien porque tuvo éxito aunque por un periodo muy corto, en aumentar la producción nacional en una proporción increíble, increíble siempre que no se tuviera fe en la visión maoista. Durante aquellos dos años, la producción. nacional se elevó en más de un $30 \%$; en ello están de acuerdo aun las estimaciones occidentales $^{21}$. ¡Y estejhecho tuvo lugar partiendo con un empleo casi total de la mano de ebra disponiblel No sé si acaso Mao liberó durante este breve perfoclo las "ilimitadas energias y creatividad de las masas" o, incluso si lo hizo, ésta no pasa de ser uṇa frase imaginativa para indicar que se trataba simplemente de un "duro y enorme es" fuerzo"; el hecho es que durante ese tiempo sẹ lograron objetivos bastante poco usuales: indiscutiblemente, el hombre parecin ser más importante que la máquina.

Si las energías cle. las masas pueden ser liberadas por incentivos morales, cada persona pasa a ser capaz de múltiples tareas: el campesino puede fabricar acero; el intelectual puede trabajar en un arrozal; el obrero de fábrica puede ser un ofícial. Cuando se piensa que la modernización económica implica aparentemente una creciente especialización, división del trabajo y profesionalismo, se despiertan serias dudas acerca de la compatibilidad de este aspecto de la visión maoísta con el progreso económico. Sin embargo, aun cuando el peso de la evidencia parecería ser contrario a los maoístas, éstos tienen algunos puntos a su favor.

En primer lugar, si la mayor parte de las gentes pueden desarrollar varios tipos de trabajo moderadamente bien, manual e intelectual, rural y urbano, la economía estaría preparada para afrontar

мT. G. Liu and K. C. Yel, oh. eil., pp. 114 ff. Sus cifras estimativas, debe hacerse notar, están basadas en conjeturas. 
cambios súbitos e importantes; podría movilizar su fuerza de trabajo . en una variedad de grandes tareas y con poea disminución de la eficiencia.

En segundo lugar, puesto que la experiencia en un trabajo puede transferirse a otros, una persona puede ser productiva en cualquier labor, en la misma medida que si se especializara en alguna. Un campesino que ha pasado varios meses en una fábrica está más capacitado para reparar maquinaria agricola, por ejemplo. En tercer lugar, una economía maoísta puede implicar más informaciones útiles que una economfa especializada y, por lo tanto, traer consigo mayor creatividad y productividad. La comunicación entre personas altamente especializadas deja de ser significativa en si misma, esto es, para decirlo con otras palabras, los especializados conocimientos de un tercero significan poco en relación con mi propio trabajo. En cambio, cuando cada persona tiene conocimientos básicos sobre una serie de materias, las experiencias de uno pueden enriquecer las potencialidades de muchos otros.

Finalmente, es muy posible que, al margen de consideraciones sobre productividad, un mundo maolsta pueda producir gentes mâs felices, gentes que puedan gozar de la vida dentro de limites mucho más amplios, mediante la oportunidad de hacer muchas cosas interesantes. Dicho sea de paso, si un pueblo trabaja más feliz, con más ahinco en sus labores, tanto mejor para ese pueblo.

\section{A MANera DE CONClusión}

Los comunistas chinos, operando con controles de hierro, como es usual entre ellos, tienen, a pesar de todo, el mérito de haber logrado notables ganancias. Han llevado a efecto con bastante éxito un programa de industrialización en gran escala; han dado prácticamente a todo su pueblo la oportunidad de educarse; han efectuado grandes avances en medicina y salud social. ISin embargo, a parejas con estos logros, cada cierto tiempo, ya sea estimulándolos o frenándolos, está la siempre presente visión maofsta. Podrfa hablar indefinidamente acerca de las posibles aplicaciones prácticas de esta visión; pero, en definitiva, nadie puede negar que es utópica. Los maoistas han sacado al campesino del pozo de ignorancia y pobreza en que se encontraba, pero ahora están tratando de transformarlo en una especie de ángel. "Escúchennos", murmuran los maolstas, "que se enriquezca primero el pueblo y luego podrás enriquecerte tú". Pero el campesino, que no pierde de vista su pedazo de tierra, también tiene oídos 
ESTUDIOS INTER N A CIONALES

para el canto clel revisionista: "primero enriquécete a ti mismo, y luego enriquecerás al pueblo" 22 .

Me prazunto, ¿en cuál de los dos llamados yace la esperanza de los pobres del mundo?

EVer el Monlhly' Revicw, lebrero 1967, pp. 2-3.

$\left[\begin{array}{llll}3 & 2 & 2\end{array}\right]$ 